\title{
Estimativa da capacidade de carga na romaria do Círio de Nazaré em Belém (PA)
}

\section{Estimate the carrying capacity of the pilgrimage of Nazareth Candle in Belém (PA, Brazil)}

\author{
Glauce Vitor da Silva, Altem Nascimento Pontes, \\ Aline Maria Meiguins de Lima
}

\begin{abstract}
RESUMO
A capacidade de carga é uma ferramenta que possibilita estimar a quantidade máxima de pessoas que podem permanecer em um determinado espaço, dentro de um intervalo de tempo. Para esta pesquisa aplicou-se o método de capacidade de carga para calcular o limite máximo de pessoas durante um evento. As análises foram realizadas considerando pressupostos de ação-resposta descrita pelo Modelo: Força motriz - Pressão - Estado - Impacto - Resposta. Como objeto de estudo trabalhou-se a grande romaria do Círio de Nazaré. Para o cálculo foram utilizadas como variáveis o espaço que constitui a trajetória do percurso, o tempo de duração da procissão e o fator solar, com a finalidade de auxiliar as entidades envolvidas na organização e segurança. Os resultados obtidos indicam que a capacidade de carga real total do evento é aproximadamente 3 (três) vezes menor que o público estimado atualmente no Círio, que é de mais de 2 milhões de romeiros. Esta situação causa diversos impactos negativos no decorrer da procissão, principalmente nas variáveis, saúde, segurança pública, saneamento ambiental e patrimônio histórico e natural.
\end{abstract}

PALAVRAS-CHAVE: Procissão Religiosa; Conforto Ambiental; Grandes Eventos; Espaços Públicos.

\section{ABSTRACT}

The load capacity is a tool which allows estimating the maximum number of people may stay in a given space within a time interval. For this research it applied the carrying capacity method to calculate the maximum amount of people during an event. Analyses were performed considering action-response assumptions described by Model: Driving force - Pressure - State - Impact - Response. As an object of study worked to great pilgrimage of Nazareth Candle. For the calculation were used as variables space which is the trajectory of the route, the time duration of the procession and the solar factor, in order to assist those involved in the organization and security. The results indicate that the actual charge capacity of the event is complete approximately three (3) times lower than that currently estimated in square cereus, which is more than 2 million pilgrims. This causes many negative impacts during the procession, especially in variables, health, public security, environmental sanitation and historical and natural heritage.

KEYWORDS: Religious Procession; Environmental Comfort; Major Events; Public Spaces. 


\section{Introdução}

A Capacidade de Carga (CC) possibilita estimar a quantidade máxima de pessoas que podem permanecer em um determinado espaço, dentro de um intervalo delimitado de tempo, por meio de cálculos baseados em fatores de correção e/ou parâmetros biofísicos, ambientais e sociais (MELO et al., 2006; BOGGIANI et al., 2007; RUSHMANN et al., 2008; LOBO et al., 2009).

Determinar o fluxo máximo aceitável de visitantes em um ambiente, sem alterações em sua dinâmica, é um desafio que vem sendo estudado por diversos pesquisadores, para o planejamento e gestão de atrativos nos destinos turísticos (SILVA et al., 2009; OLIVEIRA, 2010; ROCHA, 2011; VASCONCELOS; CÂMARA, 2012).

De acordo com Oliveira (2010), a capacidade de carga pode ser compreendida como sinônimo de capacidade ambiental. Este autor ainda afirma que:

O que a distingue é que o termo capacidade ambiental considera a interação entre o meio ambiente e as atividades humanas em diferentes escalas, simultaneamente. Já o termo capacidade de carga é mais apropriadamente usado quando somente um aspecto do meio ambiente ou de uma atividade está sendo considerado (p. 63).

O método escolhido e adaptado a esta pesquisa foi o de Cifuentes (1992) que possui como inédito a determinação do número de pessoas por trechos. De acordo com Borges e Moura (2011), o estudo da CC foi considerado um procedimento de avaliação muito preciso. Para Heras (2004), este método pode ser considerado como um modelo matemático que define em números o fluxo de visitantes ideal para determinados ambientes.

\section{CONCEPÇÃO TEÓRICA DE CAPACIDADE DE CARGA}

Originária das ciências agrárias, a CC foi inicialmente utilizada como ferramenta de avaliação de impactos no solo de fazendas em consequência da atividade pecuária (BOGGIANI et al., 2007). De origem inglesa, carrying capacity, segundo Seabra (1999), foi utilizada pela primeira vez na década de 1920, a fim de se estabelecer um número máximo de bovinos para pastagem simultânea, sem causar danos ao ambiente.

Posteriormente, o termo 'capacidade de carga' tornou-se um instrumento utilizado no planejamento do turismo de massa em áreas naturais e superficiais. De acordo com Rushmann et al. (2008), a CC passa a ser utilizada na atividade turística em 1964, por meio de Wagar em sua publicação The carrying capacity of wild lands for recreation com uma definição mais específica e direcionada à Capacidade de Carga Recreativa (CCREC).

No decorrer da década de 80 , houve muitas produções a partir do desenvolvimento de pesquisas e modelos de análise de CC ou impactos de uso público como o Washburne's Alternative Carrying Capacity Model (WASHBURNE, 1982), Limits of Acceptable Changes ou Limites Aceitáveis de Câmbio (LAC) (STANKEY et al., 1985) tendo como foco melhorar o 
manejo da visitação em áreas naturais, das condições desejadas e do uso público aceitável (TAKAHASHI, 1998) o Carrying Capacity Assessment Process (C-Cap) (SHELBY; HEBERLEIN, 1986).

Em 1990, foi criado o Visitor Impact Management (VIM) (Kuss et al.,1990). Este método foi baseado no LAC e funciona a partir de impactos considerados aceitáveis, selecionando os indicadores e seus padrões, a fim de monitorar os impactos (SEABRA, 2001).

No mesmo ano, Cifuentes et al. (1990) desenvolveram o primeiro estudo de plano de manejo no Parque Nacional de Galápagos, promovendo pela primeira vez um estudo de determinação de CC na Reserva Biológica Carara (ambos estudos na Costa Rica), onde elaboraram e desenvolveram um método de determinação da CC considerando as variáveis ambientais, físicas, ecológicas e de manejo. Atualmente, é muito utilizado em pesquisas por ser considerada uma técnica fácil e segura, na estimativa para os limites quantitativos de visitantes em uma determinada área de estudo (OLIVEIRA, 2010; ROCHA, 2011; CORDEIRO et al., 2012; VASCONCELOS; CÂMARA, 2012).

\section{O Círio de Nazaré}

O primeiro Círio de Nazaré foi realizado oficialmente em 1793, em Belém do Pará, e desde então a capital paraense recebe turistas, peregrinos e romeiros, que nos últimos anos engrandeceram ainda mais este evento, ao somarem mais de 2 milhões de pessoas, distribuídas pelas ruas do centro da cidade durante a romaria (ALVES, 2005).

A grande festa é realizada no segundo domingo do mês de outubro, e seu roteiro devocional inicia após uma missa em frente à Catedral da Sé. A peregrinação percorre cerca de $3,6 \mathrm{~km}$ até chegar a Praça Santuário Basílica Santuário de Nazaré.

De acordo com Alves (2005, p. 315), o Círio de Nazaré é "considerado como a maior procissão religiosa do Brasil, que leva às ruas de Belém, neste século XXI, milhões de pessoas". Alves (op. cit., p. 319) destaca que "o extraordinário crescimento populacional, a ampla divulgação nacional do Círio, o apelo turístico e religioso e as facilidades de transporte têm levado ao evento uma multidão". Esse autor observa as mudanças naturais no aspecto urbano, automaticamente refletidas na dinâmica da cidade, que se prepara para atender às perspectivas dos romeiros.

Mediante ao exposto, o presente artigo objetivou fazer um estudo sobre a capacidade de carga na grande romaria do Círio de Nazaré, que ocorre todos os anos, no segundo domingo do mês de outubro, período que alguns autores consideram o "Natal" dos paraenses (COUTINHO et al., 2012), na cidade de Belém, com vistas a subsidiar políticas públicas para este evento religioso. 


\section{Materiais e métodos}

O método escolhido e adaptado a esta pesquisa, foi o de Cifuentes (1992), em dois tipos de níveis de capacidade de carga: Capacidade de Carga Física (CCF) e Capacidade de Carga Real (CCR). Estes níveis possibilitam o alcance de um denominador comum, ou seja, o número de indivíduos ideal, de acordo com o algumas características do percurso do Círio, que ajudarão na compreensão dos limites:

(a) Capacidade de Carga Física (CCF): limite máximo de pessoas que podem caber em um espaço definido e em um tempo determinado, conforme descrito pela Eq. (1),

$$
\mathrm{CCF}=\mathrm{V} \times \mathrm{A} \times \mathrm{T} .
$$

Aqui $\mathrm{V}=$ número de romeiros (incluem-se como romeiros todos aqueles que estão no trajeto); $A$ = área ocupada por romeiros (adota-se que cada pessoa necessita $1 \mathrm{~m}^{2}$ de espaço, para mover-se livremente); e $\mathrm{T}=$ tempo de percurso (tempo estimado para a realização do percurso - Duração média de $6 \mathrm{~h})$.

(b) Capacidade de Carga Real (CCR): limite máximo de pessoas a partir da capacidade física; aplicando-se fatores de correção correspondentes às características particulares da área estudada, considerando variáveis ambientais, como o Fator Solar (FS), expresso na Eq. (2),

$$
\mathrm{CCR}=\mathrm{CCF} \times \mathrm{FS} \text {. }
$$

Para este cálculo foram utilizadas como variáveis o espaço que constitui a trajetória do percurso, o tempo de duração da procissão e o FS, com a finalidade de auxiliarem as entidades envolvidas na organização e segurança. Isso facilita o planejamento e melhoramento dos serviços de atendimento e prevenção de ocorrências registradas pela Cruz Vermelha durante o percurso do Círio. Além disso, ameniza possíveis desconfortos causados pelo grande número de participantes.

No que se refere ao FS e duração do percurso adotaram-se os termos expressos na Eq. (3):

$$
\mathrm{FS}=\frac{3 \mathrm{~h}(\text { Exposição à luz solar intensa }) \times 100}{6 \mathrm{~h}(\text { Média de tempo do trajeto })}=50 \% \text { limitante. }
$$

Aqui, a Média de tempo do trajeto é de $6 \mathrm{~h}$ ( $7 \mathrm{~h}$ às $13 \mathrm{~h})$, considerando $3 \mathrm{~h}$ de sol intenso (10 h às $13 \mathrm{~h})$.

Para complementar a análise, foi empregado o método de definição de indicadores associado ao Modelo: Força motriz - Pressão - Estado Impacto - Resposta (DPSIR), visando avaliar as possíveis causas/ações que podem derivar do resultado dos valores obtidos de CC. 
Os indicadores para a estruturação do modelo são as Forças Motoras (Driving Forces) que identificam as influências das atividades humanas que podem diretamente causar as Pressões (Pressures) que representam as variáveis condutoras das alterações no Estado (State) manifestando a atual condição do ambiente que geram os Impactos (Impact) que apontam os efeitos das alterações do estado, requerendo Respostas (Responses) para solucionar os problemas encontrados (FERNANDES; BARBOSA, 2011).

\section{Resultados}

Os números de romeiros, peregrinos e turistas durante o Círio impressionam a cada ano, evoluindo de cerca de 120 mil pessoas em 1940 para mais de 2 milhões no Círio de 2013, ano em que, segundo o Departamento Intersindical de Estatística e Estudos Socioeconômicos (DIEESE-PA), foi realizado "o maior Círio da história" (Tabela 1).

Tabela 1: Evolução no número médio de pessoas nos Círios das últimas décadas e anos. Belém do Pará.

Table 1: Evolution in the number of people in the recent decades and years in the Círio. Belém of Pará.

\begin{tabular}{c|c}
\hline Ano & Número médio de pessoas \\
\hline Década de 40 & 120.000 \\
\hline Década de 50 & 200.000 \\
\hline Década de 60 & 350.000 \\
\hline Década de 70 & 500.000 \\
\hline Década de 80 & 1.000 .000 \\
\hline Década de 90 & 1.500 .000 \\
\hline 2000 & 1.700 .000 \\
\hline 2005 & 1.900 .000 \\
\hline 2010 & 2.000 .000 \\
\hline 2013 & Mais de 2.000.000 \\
\hline \multicolumn{2}{c}{ Fonte: Pesquisa DIEESE/PA. } \\
\hline \multicolumn{2}{c}{ Source: Research DIEESE/PA. }
\end{tabular}

\section{Condições ambientais associadas}

É difícil estimar o tempo exato de duração da romaria, já que há dificuldade de movimentação de tantas pessoas, ainda que muitas não acompanhem todo o trajeto, e algumas busquem apenas um lugar para assistir a passagem da procissão.

De acordo com os dados da Cruz Vermelha, analisados pelo DIEESE/PA, o número de atendimentos no Círio tem aumentado ou diminuído dependendo do tempo de duração e oscilação do clima durante a procissão.

Cifuentes (1990) considera que das $12 \mathrm{~h}$ diárias de luz solar disponíveis (6 h às $18 \mathrm{~h}$ ), de $10 \mathrm{~h}$ às $15 \mathrm{~h}$ a intensidade de sol é muito forte, aumentando o desconforto em áreas descobertas. O Círio tem uma duração média de $6 \mathrm{~h}$ (das $7 \mathrm{~h}$ às $13 \mathrm{~h}$ ), onde se estima uma média de $3 \mathrm{~h}$ de limitação para a exposição à alta radiação solar. 
Em 2004, por exemplo, o Círio teve uma duração de 09:30 h, e este tempo refletiu nos dados da Cruz Vermelha, que apontaram 2.566 casos de atendimentos durante o cortejo, sendo que $55,0 \%$ destes casos ficaram concentrados em dois tipos: Desmaios, com um total de 735 casos de atendimentos registrados, equivalentes a $28,6 \%$ do total de atendimentos, e Casos de Pressão Arterial - Pressão Alta (PA) e Pressão Baixa (PB) - com um total de 679 casos de atendimentos registrados, equivalentes a $26,5 \%$ do total de atendimentos.

O Círio de 2009 teve uma duração de 05:20 h. Neste, o número de atendimentos registrados foi bem menor, aproximadamente $50,0 \%$ do registrado em 2004, totalizando 1.302 casos. Desse total, mais da metade dos atendimentos registrados pela Cruz Vermelha ficaram concentrados em três tipos: Desmaios, 354 casos; seguido de Verificação de Pressão Arterial (PA e PB), 272 casos; e Mal Estar, com o registro de 89 casos.

Nos anos seguintes, com o Círio chegando mais cedo e com uma duração de tempo menor, os números de atendimento vêm crescendo, bem como o número de participantes, no entanto os registros de ocorrências ainda são inferiores a 2004; em 2010, 2011, 2012 e 2013 as ocorrências foram respectivamente iguais a 1.494, 1280, 1968 e 2316. A Figura 1 apresenta as ocorrências mais registradas pela Cruz Vermelha, no período de 2009 a 2013, na romaria do Círio de Nazaré.

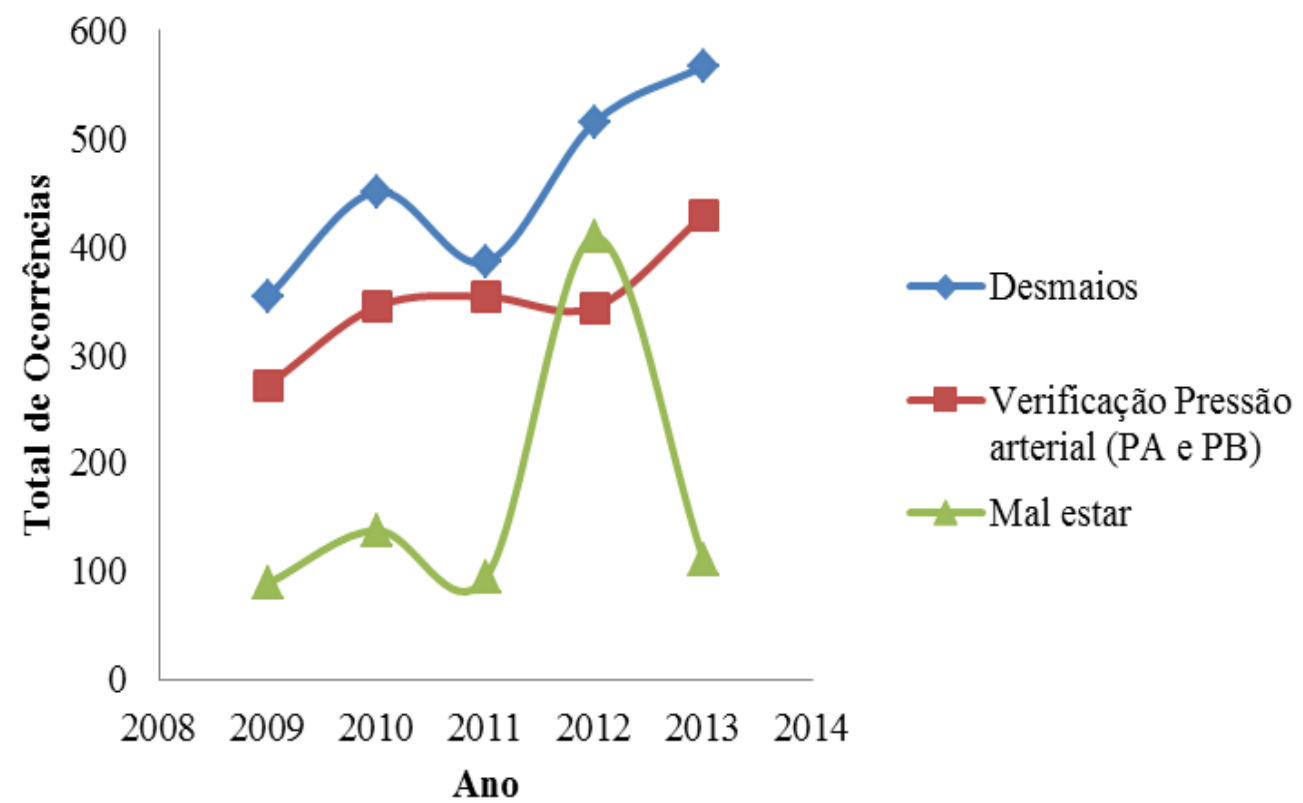

Figura 1: Tipos de ocorrências mais registradas pela Cruz Vermelha, no período de 2009 a 2013, na romaria do Círio de Nazaré, Belém do Pará. Fonte: DIEESE/PA.

Figure 1: Types of occurrences recorded by the Red Cross, in the period from 2009 to 2013 at the feast of the "Círio de Nazaré", Belém of Pará. Source: DIEESE/PA. 


\section{Aplicação do método}

Para calcular a Capacidade de Carga Física (CCF) levou-se em consideração a variação de comprimento e largura dos espaços que compõem o caminho do Círio de Nazaré, logo este trajeto foi segmentado em 7 (sete) setores: Catedral da Sé (Largo - Sé); Subida do Ver-o-Peso até a Estação das Docas (Setor 1); Avenida Presidente Vargas (Setores 2 e 3); Praça da República; Praça Santuário de Nazaré (Largo - CAN); Avenida Nazaré (Setor 4). Considerou-se 01 (uma) hora de permanência em cada, somando as seis horas de percurso (em média) (Figura 2).

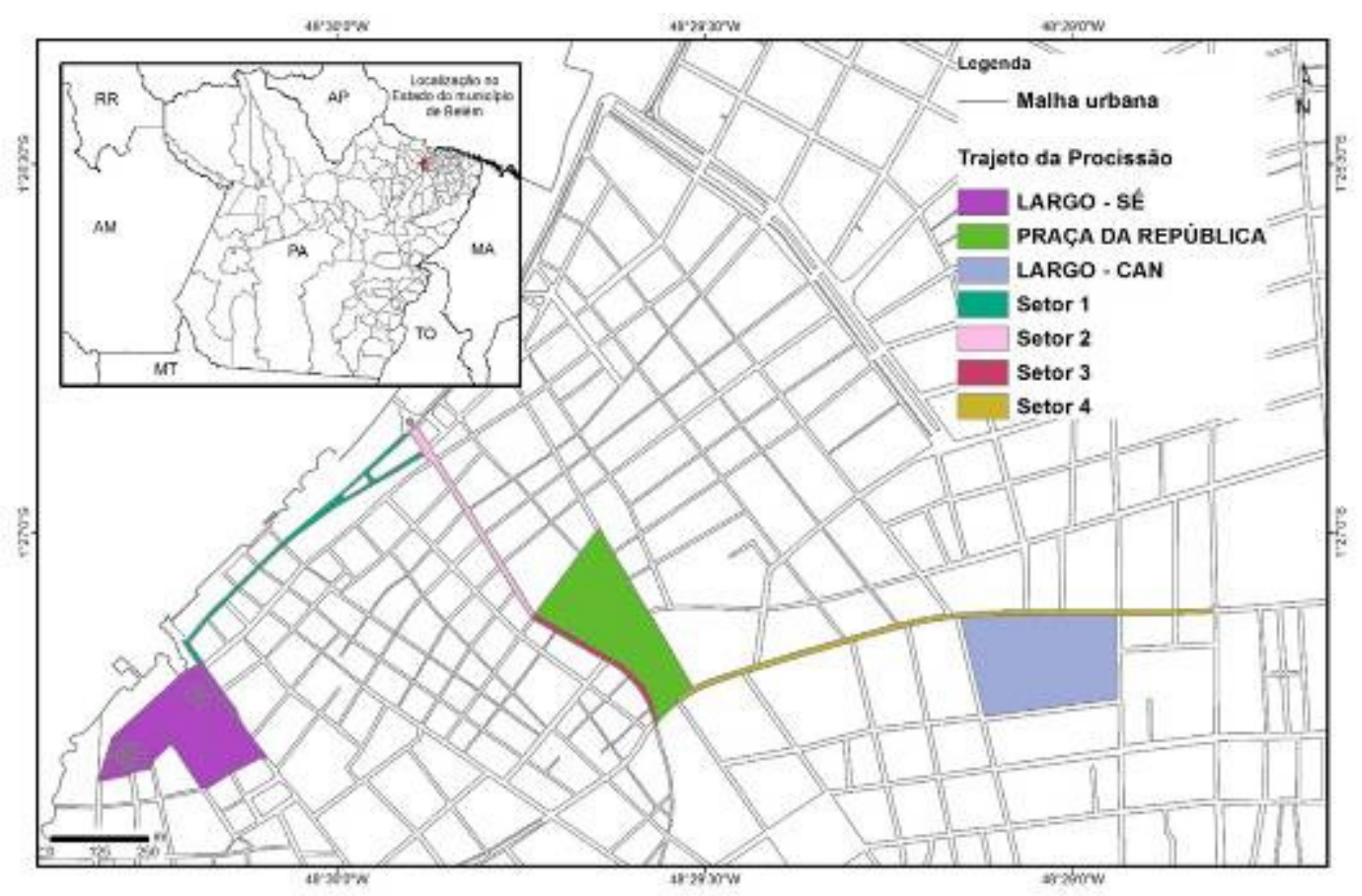

Figura 2: Trajeto do Círio de Nazaré, Belém do Pará.

Figure 2: Path of the "Círio de Nazaré", Belém of Pará.

A Tabela 2 e a Figura 2 apresentam os resultados obtidos por segmento e para o percurso total.

Tabela 2: Capacidade de Carga Física e Capacidade de Carga Real por setor e do percurso.

Table 2: Ability of Physical Load and Actual Load by Sector and route.

\begin{tabular}{|c|c|c|c|}
\hline Setores & Área do setor $\left(\mathrm{m}^{2}\right)$ & $\begin{array}{c}\text { CCF } \\
\text { (Romeiros/dia) }\end{array}$ & CCR (Romeiros/dia) \\
\hline Largo - Sé & $67.253,3$ & 190.467 & $95.233,5$ \\
\hline Setor 1 & $11.400,3$ & 34.298 & 17.149 \\
\hline Setor 2 & $8.818,3$ & 29.245 & $14.622,5$ \\
\hline Setor 3 & $5.722,3$ & 19.486 & 9.743 \\
\hline Praça da República & $71.126,6$ & 416.200 & 208.100 \\
\hline Setor 4 & $17.877,3$ & 61.269 & $30.634,5$ \\
\hline Largo - CAN & $84.917,8$ & 701.312 & 350.656 \\
\hline \multicolumn{2}{|c|}{ Valor geral do percurso } & 1.452 .277 & $726.138,5$ \\
\hline
\end{tabular}




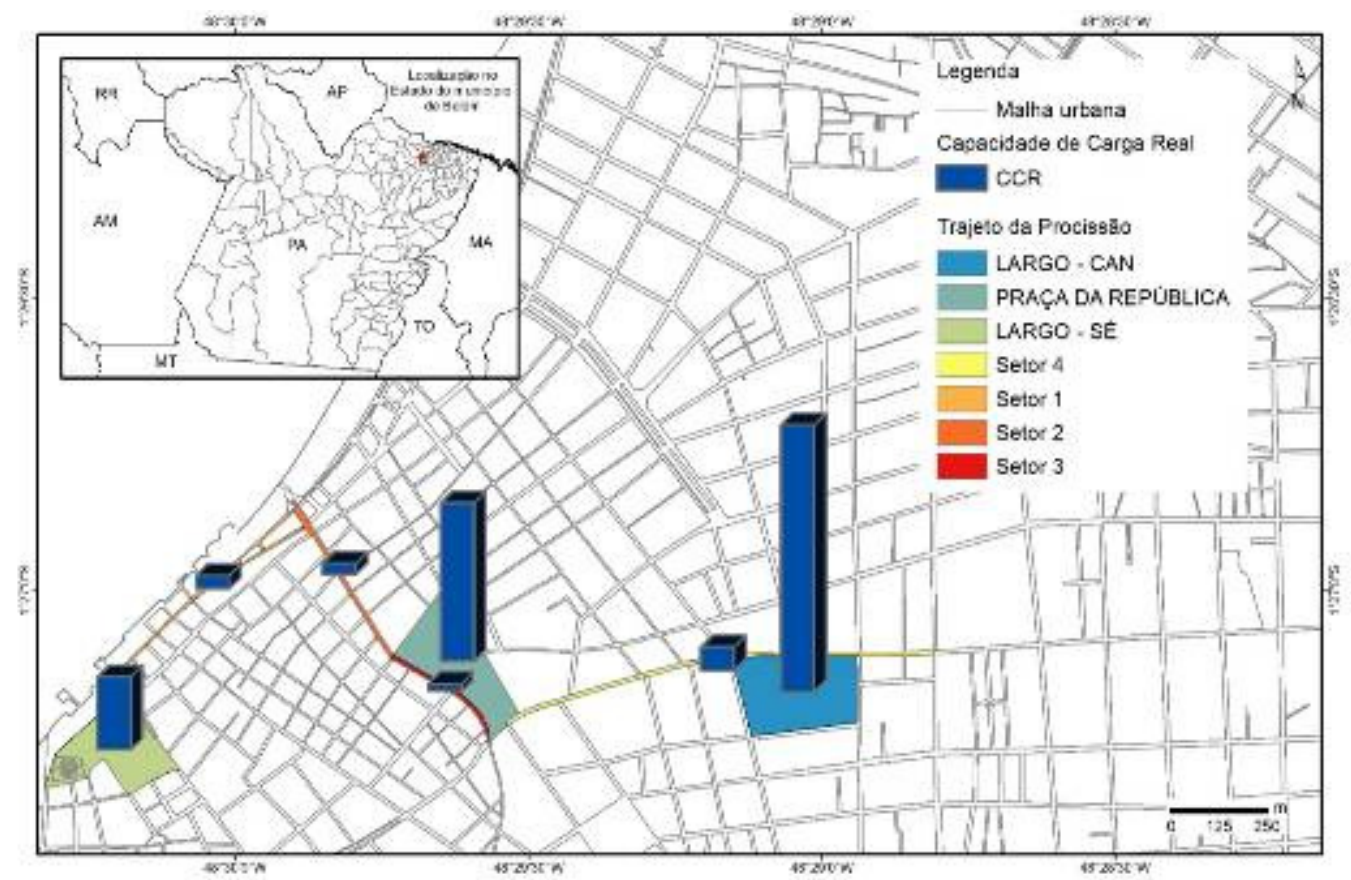

Figura 3: Variação da Capacidade de Carga Real no trajeto do Círio de Nazaré, Belém (PA) Figure 3: Variation of load capacity Real on the path of "Círio de Nazaré", Belém of Pará.

Considera-se que os primeiros metros de percurso do Círio apresentem maior conforto ambiental para os romeiros, uma vez que tanto o Largo da Sé quanto o Setor 01 estão localizados próximos às margens da Baía do Guajará, o que proporciona uma área de maior ventilação. Outro fator que favorece esses setores é o horário em que a romaria os percorre que corresponde às primeiras horas da manhã do Círio.

Nos setores 02 e 03 há um estreitamento das vias por onde passa 0 cortejo, reduzindo a $\mathrm{CC}$ e diminuindo o conforto ambiental, pois ao distanciar-se das margens do rio a romaria segue em um corredor de prédios residenciais e comerciais. Contudo, ao aproximar-se da Praça da República (Setor 03) há uma ampliação do espaço que se estende da avenida à praça, aumentando consideravelmente sua CC.

No Setor 04 e no Largo do CAN, observa-se a maior CC para o evento. Porém, essa maior concentração de pessoas demanda maior atenção dos organizadores da festa, pois correspondem aos metros finais da romaria que ocorre entre o final da manhã e início da tarde, onde a sensação térmica sofre uma elevação consequente do horário em que o sol é mais intenso e há pouca ventilação, limitada pela presença das edificações que contornam este trajeto. Deve-se considerar também o cansaço físico de romeiros e principalmente de promesseiros.

\section{Discussão}

A análise da CC por segmentos do percurso permitiu uma melhor observação do trajeto e a avaliação de alguns aspectos espaciais e temporais, que podem colaborar para o planejamento e para a distribuição de efetivo das entidades envolvidas em sua organização. 
Os resultados obtidos apontam que a CCR total do evento é aproximadamente 3 (três) vezes menor que o público estimado no Círio, que é de mais de 2 milhões de romeiros. Adaptar esta metodologia para um ambiente onde ocorre um evento público que concentra um grande número de pessoas pode contribuir para a identificação de fatores que causam ou agravam o desconforto ambiental de seus participantes, além de indicar os pontos em que há uma maior incidência, o que permite criar estratégias de intervenção para minimizar essas ocorrências.

Trabalhos que aplicaram a CC como instrumento de avaliação do potencial de aproveitamento de áreas costeiras (Melo et al., 2006; Silva et al., 2009) destacam a necessidade de avaliar seu emprego de acordo com as características do ambiente. Outras formas de emprego voltadas para atividades como espeleoturismo (LOBO et al., 2009) e o turismo histórico (OLIVEIRA, 2010) reforçam a necessidade de validar as condições locais de oferta do espaço.

Logo, dentro do planejamento do evento é necessário categorizar os serviços e a distribuição do efetivo, estabelecendo subcategorias e porcentagens de acordo com a qualidade oferecida, com base nas sugestões do Plano de Manejo local e infraestrutura básica para um atendimento de qualidade dos romeiros.

Os dados atuais apontam para um processo de elevação do número de pessoas que participam da grande romaria do Círio de Nazaré a cada ano. Observa-se que a CCR de 736.139 é aproximadamente o número de romeiros que participavam do Círio entre as décadas de 1970 e 1980, e que a CCF de 1.472.277, quase corresponde ao número de romeiros registrado até a década de 1990. E é a partir da década de 2000 que o Círio vem superando sua CC.

Um ponto de destaque é a questão do atrativo cultural e religioso. Esta força motora impulsiona o crescimento não só do número de peregrinos e romeiros, mas também da atividade turística, que apesar de sofrer influências, independe das motivações do turista para acontecer (BENI, 1997).

Uma das formas de definição destas metas está na aplicação do modelo DPSIR, onde se destaca como principal limitação de "Pressão" os valores obtidos pela CCR; e como "Força Motriz" a motivação religiosa e o investimento aplicado no turismo religioso, que faz com que o número de fiéis ao longo dos anos seja crescente (Tabela 01). Destes, derivam situações de "Estado" e "Impacto" ligadas principalmente as variáveis de saúde (resultantes das alterações na sensação térmica local, ventilação insuficiente, alimentação inadequada e estado emocional), saneamento ambiental (acúmulo de resíduos, incluindo aqueles que podem ocasionar incidentes, como vidros quebrados e metais; geração de efluentes pelo comércio de alimentos e bebidas) e de interação com o patrimônio histórico e natural (o percurso atravessa locais de intenso atrativo cultural e natural de Belém, incluindo prédios históricos, comerciais de atrativo turístico e áreas verdes destinadas ao lazer); e as possíveis ações na forma de "Resposta", conforme apresenta a Figura 4. 


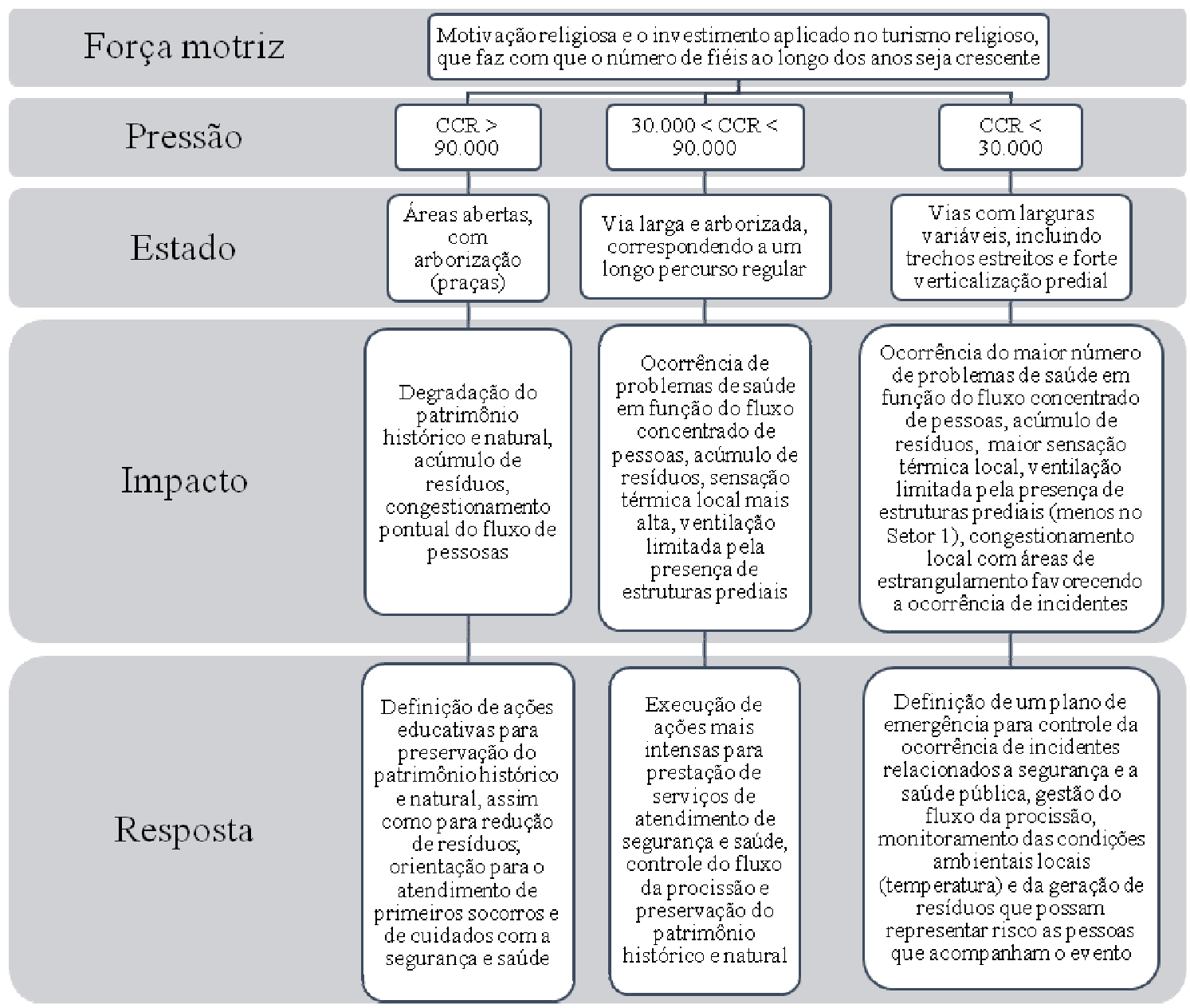

Figura 4: Análise pelo modelo DPSIR como contribuição ao melhor planejamento das ações de prevenção de incidentes do evento.

Figure 4: Analysis by the DPSIR model as a contribution for to better planning in the incident prevention on the event.

\section{Considerações finais}

A capacidade de carga real total do evento é aproximadamente 3 (três) vezes menor que o público estimado atualmente no Círio de Nazaré, que é de mais de 2 milhões de romeiros. Esta situação causa diversos impactos negativos no decorrer da procissão, principalmente nas variáveis, saúde, segurança pública, saneamento ambiental e patrimônio histórico e natural.

Os dados desta pesquisa permitem ao poder público o planejamento e adoção de políticas públicas que reduzam as inconformidades nesta grande romaria e assim permita que a cada ano mais romeiros possam participar do Círio de Nazaré. As ações mais efetivas do poder público local devem ser direcionadas prioritariamente para serviços básicos que garantam as condições de saúde, de saneamento e da preservação do patrimônio histórico e natural local, com a minimização das situações que impliquem em risco ambiental ou de segurança aos romeiros. 


\section{Referências bibliográficas}

ALVES, I. A festiva devoção no Círio de Nossa Senhora de Nazaré. Estudos Avançados, v.19 (54), p. 315-332, 2005.

BENI, M.C. Política e estratégia de desenvolvimento regional: planejamento integrado do turismo local. São Paulo: SENAC, 1997.

BOGGIANI, P.C.; SILVA, O.J.; GESICKI, A.L.D.; GALLATI, E.A.B.; SALLES, L.O.; LIMA, M.M.E.R. Definição de capacidade de carga turística das cavernas do Monumento Natural Gruta do Lago Azul (Bonito, MS). Geociências, v. 26 (4), 333348, 2007.

BORGES, J.L.C.; MOURA, A.C.M. Abordagens Metodológicas sobre a Capacidade de Carga Turística e Sua Aplicação Quantitativa em Ambiente Geoespacial. In: Encontro Nacional da Associação Brasileira de Estudos Regionais e Urbanos. Anais IX ENABER, Natal (RN), Brasil, 2011.

CIFUENTES, M. et al. Capacidad de carga de la Reserva Biológica Carara. Costa Rica: Programa de Manejo Integrado de Recursos Naturales - Centro Agronómico Tropical de Investigación y Enseñanza (CATIE), 1990.

CIFUENTES, M. et al. Determinacion de capacidad de carga en áreas protegidas. Turialba (Costa Rica): CATIE, 1992.

CORDEIRO, I. D; KÖRÖSS, N.; SELVA, V. S. F. (2012). DETERMINACIÓN DE LA CAPACIDAD DE CARGA TURÍSTICA EI caso de Playa de Tamandaré Pernambuco - Brasil. Estudios y Perspectivas en Turismo, v. 21, 1630 - 1645, 2012.

COUTINHO, S.C.; LIMA, A.C.O.; FARAH, J.F. Manifestação cultural: música e fé no Círio de Nossa Senhora de Nazaré, Belém (PA). Revista Brasileira de Ecoturismo, v.5, n.3, 2012,502-511, 2012.

DEPARTAMENTO INTERSINDICAL DE ESTATÍSTICAS E ESTUDOS SOCIOECONÔMICOS DO ESTADO DO PARÁ. Informação e documentação Belém, 2013.

FERNANDES, M.F.; BARBOSA, M.P. Aplicações dos Indicadores Socioeconômicos e Ambientais no Modelo DPSIR (Força Motriz/Pressão/Estado/Impacto/Resposta) e Influências na Desertificação nos Municípios de Araripina-PI, Crato e Barbalha-CE e Marcolândia-P. Revista Brasileira de Geografia Física, v.04, 722-737, 2011.

LOBO, H.A.S.; PERINOTTO, J.A.J.; BOGGIANI, P.C. CAPACIDADE DE CARGA TURÍSTICA EM CAVERNAS: ESTADO-DA-ARTE E NOVAS PERSPECTIVAS. Espeleo-Tema, v. 20, 37-47, 2009.

MELO, R.S.; SILVA, M C.B.C.; LIMA, E.R.V.; NISHIDA, A.K. Estimativa da capacidade de carga recreativa dos ambientes recifais da Praia do Seixas (Paraíba - Brasil). Turismo - Visão e Ação, v. 8 (3), 411-422, 2006.

OLIVEIRA, F.V. Capacidade de carga em cidades históricas. Revista Brasileira de Pesquisa em Turismo, v. 4 (1), 61-75, 2010.

PÉREZ DE LAS HERA, M. Manual del Turismo sostenible: como conseguir un turismo social, económico y ambientalmente responsable. Madrid, Barcelona, México: Mundi-prensa, 2004.

ROCHA, J.M. DESENVOLVIMENTO E SUSTENTABILIDADE DO TURISMO: Preceitos da teoria da capacidade de carga turística. Revista Rosa dos Ventos, v. 3 (3), 382-3892, 2011. 
RUSHMANN, D.V.M.; PAOLUCCI, L.; MACIEL, N.A.L. Capacidade de Carga no Planejamento Turístico: Estudo de caso da Praia Brava - Itajaí frente à implantação do Complexo Turístico Habitacional Canto da Brava. Revista Brasileira de Pesquisa em Turismo, v. 2 (2), 2-28, 2008.

SEABRA, L. S. Determinação da capacidade de carga turística para a trilha principal de acesso à cachoeira de Deus - Parque Municipal Turístico - Ecológico de Penedo - Itatiaia, RJ. 1999. 162 f. Dissertação (Mestrado em Ciências Ambientais) - Universidade Federal Fluminense. Niterói, 1999.

SILVA, I.R.; SOUZA FILHO, J.R.; BARBOSA, M.A.L.; REBOUÇAS, F., MACHADO, R.A.S. Diagnóstico ambiental e avaliação da capacidade de suporte das praias do bairro de Itapoã, Salvador, Bahia. Sociedade \& Natureza, Uberlândia, v. 21 (1), 71-84, 2009.

STANKEY, G. H.; COLE, D. N.; LUCAS, R. C; PETERSEN, M. E; FRISSELI, S. S. The Limits of Acceptable Change (LAC) system for wilderness planning. General Technical Report INT. USDA. Forest Service, Ogden. 176, 1-37, 1985.

TAKAHASHI, L.Y. Caracterização dos Visitantes, suas preferências e percepções e avaliação dos impactos da visitação pública em duas Unidades de Conservação do Estado do Paraná. 1998. Tese (Doutorado em Ciências Florestais) - Universidade Federal do Paraná, Curitiba, 1998.

VASCONCELOS, C.S.; CÂMARA, J.B.D. EVALUACIÓN DE LA CAPACIDAD DE CARGA FÍSICA DEL PARQUE MUNICIPAL DEL ITIQUIRA, FORMOSA (GO), BRASIL. Estudios y Perspectivas en Turismo, v. 21, 996 - 1012, 2012.

WASHBURNE, R.F. Wilderness Recreation Carrying Capacity: are numbers necessary? Journal of Forestry, v. 80 (1), 726-728, 1982.

Glauce Vitor da Silva: Universidade Federal do Pará, Belém, PA, Brasil.

E-mail: glaucevitor@yahoo.com.br.

Link para o Lattes: http://lattes.cnpq.br/0491000360565155

Altem Nascimento Pontes: Universidade do Estado do Pará, Belém, PA, Brasil.

E-mail: altempontes@hotmail.com.

Link para o currículo Lattes: http://lattes.cnpq.br/5993352890364998

Aline Maria Meiguins de Lima: Universidade Federal do Pará, Belém, PA, Brasil.

E-mail:slima@ufpa.br.

Link para o currículo Lattes: http://lattes.cnpq.br/6572852379381594

Data de submissão: 08 de outubro de 2014

Data de recebimento de correções: 12 de maio de 2015

Data do aceite: 12 de maio de 2015

Avaliado anonimamente 